Research Article

\title{
Co-administration of Fluoxetine Alters the Steady State Pharmacokinetics of Fluconazole after Multiple Oral Administration in Dogs
}

\author{
Iman Y. Zaghloul, Yosef A. Asiri, Lamya S. Alnaim, and Badraddin M. Al-Hadiya \\ Department of Clinical Pharmacy, College of Pharmacy, King Saud University, P.O. Box 22452, Riyadh 11495, Saudi Arabia
}

Correspondence should be addressed to Iman Y. Zaghloul, zaghloul@ksu.edu.sa

Received 30 January 2009; Revised 15 May 2009; Accepted 23 June 2009

\begin{abstract}
Objectives. Fluconazole is an antifungal agent which has become the mainstay treatment of opportunistic fungal infections in immuno-compromized patients. Fluoxetine is a selective serotonine reuptake inhibitor used in the treatment of psychiatric disorders. In the current study we investigated the effect of chronic administration of fluoxetine on the steady state pharmacokinetics parameters of fluconazole. Methods. The pharmacokinetics of Fluconazole, following $10 \mathrm{mg} / \mathrm{kg}$ single and multiple oral dosing for 10 days, was determined in dogs. Subsequently, the effect of $2 \mathrm{mg} / \mathrm{kg}$ fluoxetine given for 10 days, on the pharmacokinetics of Fluconazole was investigated. Results. The co-administration resulted in significant reduction of $40.1 \%$ and $35.6 \%$ in $\mathrm{AUC}_{0-\infty}$, and $\mathrm{C}_{\max }$, respectively compared to fluconazole alone. A significant alteration of $V_{s s / F}$ was also seen as it increased from $0.242 \pm 0.04$ to $0.654 \pm 0.171 / \mathrm{kg}(P<.01)$. Accordingly, a significant reduction in $K_{\mathrm{el}}$ from $0.048 \pm 0.01 \mathrm{hr}-1$ to $0.031 \pm 0.01$ was detected $(P<.01)$. Conclusion. fluoxetine reduced plasma concentration of fluconazole. The mechanism of the interaction is probably the inhibition of OATP or other transporters in the intestinal wall. This interaction may have significant clinical importance because reduction in fluconazole may lead to treatment failure of fungal infection.
\end{abstract}

Copyright (c) 2009 Iman Y. Zaghloul et al. This is an open access article distributed under the Creative Commons Attribution License, which permits unrestricted use, distribution, and reproduction in any medium, provided the original work is properly cited.

\section{Introduction}

Fluconazole is a fluorine-substituted, bis-triazole antifungal agent. Its mechanism of action involves interruption of the conversion of lanosterol to ergosterol via binding to fungal cytochrome P450 and subsequent disruption of fungal membrane [1]. Fluconazole inhibits CYP3A isozymes which are the most abundant cytochrome enzymes in humans. They account for $30 \%$ of the cytochrome P450 enzymes in the liver and are also substantially expressed in the intestines [2]. Members of this subfamily are involved in many clinically important drug interactions. The use of larger doses of some drugs such as cyclosporine, phenytoin, oral hypoglycemics and warfarin can result in considerable drug interactions [3]. Fluconazole is much less lipophilic than other azole antifungals, and this leads to excellent penetration throughout the body, low protein binding and water solubility. Moreover, oral forms are quickly absorbed and bioavailability is nearly complete [4]. Distribution is extensive throughout the tissues and allows the treatment of a variety of systemic fungal infections. The average elimination half life is 31.6 hours long. Fluconazole is stable to metabolism, which results in excellent efficacy and safety in a wide range of clinical situations. Renal excretion accounts for the majority of drug elimination [4].

Fluoxetine hydrochloride is a serotonin reuptake inhibitor that is used in the treatment of depression and obsessive- compulsive disorder (OCD) and it is currently marketed under the name of Prozac [5]. Fluoxetine is rapidly metabolized to its desmethyl metabolite, norfluoxetine which has similar pharmacological activity. Both fluoxetine and its metabolite are eliminated by oxidative metabolism via the CYP450 system and may inhibit the oxidative metabolism of other drugs to various degrees [6].

Since most psychiatric disorders are chronic disorders requiring long-term treatment, there is a considerable opportunity for fluoxetine to be used at the same time with a wide range of drugs especially in hospitalized patients giving rise to potential drug interactions and their untoward consequences. Fluoxetine is a substantial inhibitor of CYP2D6 
with mild effects on CYP3A/4, and may also have effects on CYP2C9/10 and CYP2C19. Effects on drugs metabolized by these enzymes can persist for many weeks after fluoxetine discontinuation due to the long half-life of fluoxetine and its active metabolite norfluoxetine [7]. An increased risk of pharmacokinetic drug interactions is the immediate clinical consequence of the inhibitory effects of these drugs on CYP isoenzymes $[8,9]$. Since both drugs are strong inhibitors to the izoenzyme system, their co-administrations, on a chronic basis, could lead to different types of drug interactions. Since fluconazole has been proven to have similar pharmacokinetic properties regarding absorption, distribution, metabolism and excretion among different species (mice, rats, dogs and humans), we used the dog in the current study.

In the current study, we attempted to investigate the pharmacokinetics of Fluconazole when co-administered with fluoxetine for a period of three weeks in dogs. The study consisted of two phases. In phase I, the pharmacokinetics of Fluconazole, following single and multiple oral dosing for 10 days, was determined. While in phase II, the effect of co-administration of fluoxetine on the pharmacokinetics of Fluconazole was investigated.

\section{Materials and Methods}

\subsection{Pharmacokinetic Studies}

2.1.1. Animals. Six male beagle dogs with an average weight of $14.6 \pm 2.4 \mathrm{~kg}$ were used for the study. Animals were kept in separate cages and used for single- and multiple-dose pharmacokinetics of fluconazole and for the drug interaction study with fluoxetine. Animals were fasted for 12 hours before dosing and for 4 hours after dosing the drug.

2.1.2. Drug Dosing Suspensions. Diflucan $150 \mathrm{mg}$ capsules (Pfizer) and Apo-fluoxetine $20 \mathrm{mg}$ capsule (ICI) were purchased from local market. Aqueous suspension of both medications was freshly prepared daily and immediately before dosing. The exact dose was given based on each dog's weight after mixing vigorously using a vortex. The suspension of the capsule was checked for homogeneity and content using the same HPLC assay.

2.1.3. Experimental Dosing Protocol. Six male Beagle dogs were used for the current study. A total dose of $10 \mathrm{mg} / \mathrm{kg}$ of fluconazole was administered on a fasted Stomach (12 hours fast) for one week. Oral doses of the suspension were given by esophageal tube and washed with water $(\sim 10 \mathrm{~mL})$. Blood samples were drawn from the cephalic vein by venipuncture on day 1 (single-dose pharmacokinetics) and day 10 (multiple-dose pharmacokinetics) at the following intervals; 0 (predose), 0.25, 0.5, 1, 2, 4, 6, 8, 12, 24, 48 and 72 hours after dosing with the first dose and only up to 24 hours on day 10. Plasma samples were obtained by centrifugation and kept at $-20^{\circ} \mathrm{C}$ pending HPLC analysis. After blood sampling on day 10; dogs were co-administered oral fluoxetine daily along with fluconazole which continued for another 10 days. Fluoxetine was administered at a dose of
$2 \mathrm{mg} / \mathrm{kg}$ and that of fluconazole was kept at $10 \mathrm{mg} / \mathrm{kg}$. Blood sampling was carried out on day 21 at the same time intervals (up to 72 hours) and plasma was separated and stored frozen until analysis.

\subsection{HPLC Assay of Fluconazole}

2.2.1. Reagents. All solvents used were of HPLC grade. Other reagents and chemicals were of analytical grade. HPLC grade water was obtained from Milli-Q-Apparatus (Millipore, Bedford, Mass, USA). Fluconazole and Phenacetin were obtained from Sigma Co., St. Louis, Mass, USA.

2.2.2. Apparatus. The HPLC system (Waters Associates, Milford, Mass, USA) consisted of a solvent delivery system controller (M-2690), separations module, an autosampler, a column oven, dual absorbance detector (M-2487) and millennium software for chromatographic determination and evaluation.

Chromatographic separations were performed using $5 \mu \mathrm{m}$ symmetry $\mathrm{C}_{18}$ stainless steal column $(150 \mathrm{~mm} \times$ $3.9 \mathrm{~mm}$ i.d) coupled with a guard column of same material $(20 \mathrm{~mm} \times 3.9 \mathrm{~mm}$ i.d. $)$.

2.2.3. Standard Solutions. A stock solution of Fluconazole was prepared in a $100 \mathrm{~mL}$ flask by dissolving $100 \mathrm{mg}$ Fluconazole in methanol to make $100 \mathrm{~mL}$, then sonicated for 5 minutes and stored at $-70^{\circ} \mathrm{C}$. This stock solution was diluted 10 -fold and 100-fold in methanol to give working standard solutions of $100 \mu \mathrm{g} / \mathrm{mL}$ and $10 \mu \mathrm{g} / \mathrm{mL}$, respectively. The stock solution of internal standard was prepared by dissolving $50 \mathrm{mg}$ phenacetin in $50 \mathrm{~mL}$ of methanol and stored at $-70^{\circ} \mathrm{C}$. This stock solution was diluted daily 20 -fold in methanol to give a working standard solution of $50 \mu \mathrm{g} / \mathrm{mL}$.

2.2.4. Chromatographic Conditions. The mobile phase consisted of $30 \%$ methanol in $0.01 \mathrm{M}$ sodium acetate buffer solution of PH 5.0 (adjusted with 37\% hydrochloric acid). Mobile phase was degassed daily by passing it through a $0.22 \mathrm{~mm}$ membrane filter (Millipore, Bedford, Mass, USA).

The mobile phase was pumped isocratically at a flow rate of $1.5 \mathrm{~mL} / \mathrm{min}$ at ambient temperature. The effluent was monitored using UV detector set at a wavelength of $210 \mathrm{~nm}$.

2.2.5. Analysis. Appropriate amounts of stock and working standards of Fluconazole solution are added to $1.5 \mathrm{~mL}$ eppendorf tubes, and then $40 \mu \mathrm{L}$ of the working standard solution of internal standard (phenacetin $(50 \mu \mathrm{g} / \mathrm{mL})$ ) was added to each tube. The solution was evaporated to dryness under a gentle stream of nitrogen. A volume of $500 \mu \mathrm{L}$ of drug free dog plasma was added to each tube and the tubes were vortex for 30 seconds. This mixing was repeated after adding $160 \mu L$ of $0.01 \mathrm{M}$ sodium acetate buffer of $\mathrm{pH}$ 5.0. Next, $400 \mu L$ of the mixture was transported to ultra free-MC tubes (Millipore, Bedford, Mass, USA) of $0.5 \mathrm{~mL}$ capacity and centrifuged at $13000 \mathrm{rpm}$ for 10 minutes. Aliquots were loaded in the autosampler tray and volumes of $50 \mu \mathrm{L}$ were injected into the chromatograph. 
2.3. Pharmacokinetics Analysis. The mean plasma concentrations data were analyzed using model-independent methods. RSTRIP (RSTRIP VER 5 Micromath Scientific Software, Salt Lake City, Utah, USA), a curve stripping, and PCNONLIN (PCNONLIN VER 4 Statistical Consultant Inc., Apex, NC 1992), nonlinear least squares regression, computer programs, were utilized to estimate the pharmacokinetic parameters of fluconazole for single, multiple and combination treatments. The noncompartmental analysis for extravascular administration in PCNONLIN was used to measure the area under fluconazole concentration time curve (AUC), the area under the first moment of the curve (AUMC), the mean residence time (MRT $=\mathrm{AUMC} / \mathrm{AUC})$ and the elimination half-life $\left(t_{1 / 2}\right)$. The apparent total clearance $(\mathrm{Cl} / F)$ and apparent volume of distribution at steady-state $\left(V_{\mathrm{ss}} / F\right)$ were calculated using noncompartmental equations where, $\mathrm{Cl} / F=$ (Dose/AUC) and $V_{\mathrm{ss}} / F=(\mathrm{Cl} * \mathrm{MRT})$. After multiple dosing the AUC was estimated during the dosing interval $(\tau)$. Drug accumulation was measured by $C_{\max , s s} / C_{\max , 1}$, where $C_{\max , s s}$ is the maximum concentration after the last dose (at steadystate) and $C_{\max , 1}$ is the maximum concentration after the first dose.

2.4. Statistical Analysis. Pharmacokinetic parameters for each group were compared statistically by ANOVA using GraphPad InStat tm software v2.04 (Ralf Stahlman, Purdue University), with Tukey-Kramer multiple Comparisons testing if the differences were significant. The $t$-test was used to examine the concentration difference at each day, and oneway analysis of variance (ANOVA) was employed to evaluate the reproducibility of the assay. The level of confidence was $95 \%$.

\section{Results}

The mean plasma concentration-time curves of Fluconazole administered orally on different occasions as single- and multiple-doses and in combination with fluoxetine are represented in Figure 1. As shown in the figure the peak concentrations were achieved within 2 hours of dosing and it was similar on the three different sampling days. Individual Pharmacokinetics parameters of Fluconazole in each dog following the administration of the single-dose of Fluconazole, multiple-doses and the co-administration with fluoxetine are shown in Table 1. As shown in the table, the mean maximum concentrations $\left(C_{\max }\right)$ and the area under the plasma concentrations $\left(\mathrm{AUC}_{0-\infty}\right)$ after the singledose were $12.55 \mu \mathrm{g} / \mathrm{mL}$ and $376 \mu \mathrm{g} . \mathrm{hr} / \mathrm{mL}$, respectively. The mean elimination half-life $\left(t_{1 / 2}\right)$ and the systemic clearance $\left(\mathrm{Cl}_{\text {sys }}\right)$ were 18.4 hours and $7.81 \mathrm{~mL} / \mathrm{min}$. Mean volume of distribution $\left(V_{\beta} / F\right)$ calculated from plasma clearance and a $K_{\mathrm{el}}$ value was $0.82 \mathrm{~L} / \mathrm{kg}$. This volume of distribution is approximate to that for total body water and suggests that the drug is not extensively bound to tissues. Following daily administration of fluconazole for 10 days every 24 hours (to verify reaching a steady-state), the mean maximum plasma concentrations determined visually and was reached at about 2 hours in all the dogs with a maximum concentrations of $37.83 \mu \mathrm{g} / \mathrm{mL}$ (range of $33.02-37.8 \mu \mathrm{g} / \mathrm{mL}$ ) and $\mathrm{AUC}_{0-24} \mathrm{hr}$ of

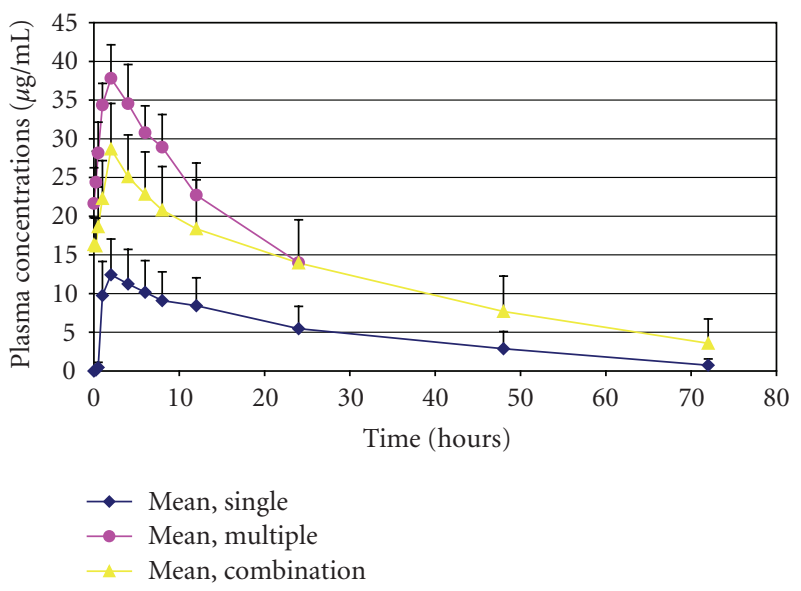

Figure 1: Mean plasma concentrations $( \pm S D)$ of fluconazole following oral administration of single- and multiple-dose of $10 \mathrm{mg} / \mathrm{kg}$ in the dog with and without fluoxetine.

$590.64 \mu \mathrm{g} . \mathrm{hr} / \mathrm{mL}$. An accumulation index of 1.61 is expected at this dosing rate and the predicted half-life. However, the actual accumulation index calculated based on the measured $C_{\max , s s} / C_{\max , 1}$ was 3.01 . The elimination half-life was not statistically significant after multiple dosing compared to the single-dose ( $15.03 \pm 3.30$ hours versus $18.4 \pm 5.23$ hours). The Clearance CL/F and volume of distribution $V_{\text {ss }} / F$ calculated after the multiple dosing were $4.13 \mathrm{~mL} / \mathrm{min}$ and $0.242 \mathrm{~L} / \mathrm{kg}$, respectively.

Co-administration of fluoxetine orally with fluconazole for another 10 days at a dose of $2 \mathrm{mg} / \mathrm{kg}$ has resulted in significant reduction of $40.1 \%$ and $35.6 \%$ in AUC and $C_{\max }$, respectively compared to fluconazole alone (Table 2). It is worth mentioning that the reduction in AUC and $C_{\max }$ showed wide variability among the six dogs with a range of $15.2-58.6 \%$ and (-) $0.6-46.2 \%$, respectively. (The reduction ranged from negative values to positive values.) It is shown in Table 1 that 2 of the dogs did not reflect any reduction in $C_{\max }$ (Dog 2\&7). The maximum concentrations were reached in 2 hours which was similar to that of fluconazole alone. The mean $C_{\max }$ was reduced significantly from 37.8 to $28.7 \mu \mathrm{g} / \mathrm{mL}$ following the administration of fluoxetine $(P<.05)$. A significant reduction in $K_{\mathrm{el}}$ was seen after the administration of fluoxetine; 0.031 versus $0.048 \mathrm{hr}-1(P<$ $.01)$. Similarly, there was a significant increase of $V_{\text {ss }} / F$ after the co-administration of fluoxetine, $(P<.01)$. No significant change was seen in the clearance values after both treatments $(P>.05)$.

Compartmental analysis of the data was conducted for all three treatments groups and the mean parameters are shown in Table 3. Compartmental analysis showed that the data was well described by a typical two compartments open model with first-order absorption on all the measurements days. The observed minus the predicted sum of square of residuals were reasonably small and randomly distributed around the predicted lines and the correlation coefficient $(r)$ ranged between 0.9199 and 0.9991 . Although there was a $41.5 \%$ reduction in mean $K_{\mathrm{a}}$ when fluoxetine was coadministered with Fluconazole, however, the differences were 
TABLE 1: Pharmacokinetics of fluconazole in dogs following the administration of a $10 \mathrm{mg} / \mathrm{kg}$ single oral dose, a $10 \mathrm{mg} / \mathrm{kg}$ multiple oral dose, and $10 \mathrm{mg} / \mathrm{kg}$ orally with $2 \mathrm{mg} / \mathrm{kg}$ fluoxetine on a multiple-dose regimen.

\begin{tabular}{|c|c|c|c|c|c|c|c|c|c|c|c|c|}
\hline & \multicolumn{3}{|c|}{$C_{\max }, \mathrm{mg} / \mathrm{L}$} & \multicolumn{3}{|c|}{$\mathrm{AUC}_{0-t}, \mathrm{mg} \cdot \mathrm{hr} / \mathrm{L}$} & \multicolumn{3}{|c|}{$\mathrm{AUC}_{0-\infty}, \mathrm{mg} \cdot \mathrm{hr} / \mathrm{L}$} & \multicolumn{3}{|c|}{$K_{\mathrm{el}}, \mathrm{hr}-1$} \\
\hline & S & M & $\mathrm{C}$ & S & M & $\mathrm{C}$ & S & M & $\mathrm{C}$ & $S$ & M & $\mathrm{C}$ \\
\hline Dog 1 & 19.08 & 37.55 & 28.04 & 550.4 & 592.7 & 476.80 & 595.1 & 897.52 & 540.7 & 0.034 & 0.048 & 0.035 \\
\hline $\operatorname{Dog} 2$ & 7.627 & 37.8 & 38.03 & 285.3 & 631.71 & 722.50 & 294.9 & 1145.96 & 1319.7 & 0.051 & 0.034 & 0.017 \\
\hline $\operatorname{Dog} 4$ & 19.34 & 39.44 & 26.66 & 606.7 & 626.997 & 427.90 & 679.5 & 948.38 & 532.4 & 0.029 & 0.056 & 0.029 \\
\hline $\operatorname{Dog} 6$ & 9.538 & 45.92 & 24.73 & 222.8 & 744.11 & 316.00 & 232.4 & 1256.8 & 520.9 & 0.043 & 0.041 & 0.025 \\
\hline $\operatorname{Dog} 7$ & 10.84 & 33.23 & 34.25 & 208.5 & 501.34 & 460.96 & 238.2 & 678.61 & 512.33 & 0.028 & 0.056 & 0.038 \\
\hline $\operatorname{Dog} 9$ & 8.88 & 33.02 & 20.3 & 142.2 & 446.99 & 285.50 & 215.9 & 735.38 & 304.7 & 0.058 & 0.054 & 0.044 \\
\hline Mean & 12.55 & 37.83 & 28.67 & 336.0 & 590.64 & 448.28 & 376.0 & 943.78 & 621.79 & 0.04 & 0.048 & 0.031 \\
\hline \multirow[t]{3}{*}{ S.D. } & 5.26 & 4.70 & 6.46 & 194.1 & 105.00 & 155.29 & 205.90 & 225.70 & 353.37 & 0.01 & 0.009 & 0.01 \\
\hline & \multicolumn{3}{|c|}{$t_{1 / 2}$, hours } & \multicolumn{3}{|c|}{ MRT, hours } & \multicolumn{3}{|c|}{$\mathrm{Cl} / F, \mathrm{~mL} / \mathrm{min}$} & \multicolumn{3}{|c|}{$V_{\mathrm{ss}} / F, \mathrm{~L} / \mathrm{kg}$} \\
\hline & $S$ & M & $\mathrm{C}$ & S & $\mathrm{M}$ & $\mathrm{C}$ & S & M & $\mathrm{C}$ & S & M & $\mathrm{C}$ \\
\hline $\operatorname{Dog} 1$ & 20.43 & 15.08 & 19.96 & 29.75 & 15.58 & 32.333 & 4.20 & 4.22 & 5.24 & 0.49 & 0.26 & 0.678 \\
\hline $\operatorname{Dog} 2$ & 13.70 & 20.62 & 39.76 & 25.96 & 19.17 & 53.96 & 9.61 & 4.49 & 3.92 & 0.67 & 0.30 & 0.747 \\
\hline $\operatorname{Dog} 4$ & 23.78 & 12.37 & 24.10 & 33.96 & 12.98 & 36.638 & 3.75 & 3.99 & 5.84 & 0.50 & 0.20 & 0.839 \\
\hline $\operatorname{Dog} 6$ & 16.15 & 16.92 & 28.21 & 23.6 & 18.13 & 41.58 & 10.76 & 3.36 & 7.91 & 1.00 & 0.24 & 1.316 \\
\hline $\operatorname{Dog} 7$ & 24.37 & 12.29 & 18.31 & 16.61 & 12.86 & 28.418 & 10.85 & 4.99 & 5.42 & 1.45 & 0.25 & 0.597 \\
\hline $\operatorname{Dog} 9$ & 11.99 & 12.89 & 15.82 & 14.77 & 8.63 & 26.623 & 7.72 & 3.73 & 5.84 & 0.80 & 0.19 & 0.932 \\
\hline Mean & 18.40 & 15.03 & 24.36 & 24.11 & 14.56 & 36.59 & 7.81 & 4.13 & 5.70 & 0.82 & 0.24 & 0.85 \\
\hline S.D. & 5.23 & 3.30 & 8.73 & 7.43 & 3.89 & 10.11 & 3.18 & 0.57 & 1.29 & 0.36 & 0.04 & 0.26 \\
\hline
\end{tabular}

S: single-dose study, M: multiple-dose study, C: combination study, $C_{\max }$ : maximum concentration, $\mathrm{AUC}_{0-t}$ : area under the concentration curve from time zero to the end of the dosing interval, $\mathrm{AUC}_{0-\infty}$ : area under the concentration curve from time zero to infinity, $K_{\mathrm{el}}$ : elimination rate constant, $t_{1 / 2}$ : half-life, MRT: mean residence time, $\mathrm{Cl} / \mathrm{F}$ : clearance, $V_{\mathrm{ss}} / F$ : volume of distribution.

TABLE 2: Effect of fluoxetine on the mean pharmacokinetic parameters $( \pm S D)$ of fluconazole at steady-state alone and in combination with fluoxetine.

\begin{tabular}{lccc}
\hline Parameters & Fluconazole & Fluconazole + Fluoxetine & \% Reduction \\
\hline$C_{\max }, \mathrm{mg} / \mathrm{L}$ & $37.83 \pm 4.70$ & $28.70^{*} \pm 6.46$ & $35.6 \pm 8.86$ \\
$T_{\max }, \mathrm{hr}$ & 2.0 & 2.0 & $24.1 \pm 5.30$ \\
$\mathrm{AUC}_{0-t}, \mathrm{mg} \cdot \mathrm{hr} / \mathrm{L}$ & $590.641 \pm 105.0$ & $448.28 \pm 155.29$ & $40.1 \pm 17.68$ \\
$\mathrm{AUC}_{0-\infty}, \mathrm{mg} \cdot \mathrm{hr} / \mathrm{L}$ & $943.78 \pm 225.7$ & $621.79^{*} \pm 353.37$ & $0.031^{* * *} \pm 0.01$ \\
$K_{\mathrm{e}}, \mathrm{hr}-1$ & $0.048 \pm 0.009$ & $24.36^{*} \pm 8.73$ & $36.59^{* * *} \pm 10.11$ \\
$t_{1 / 2}, \mathrm{hr}$ & $15.028 \pm 3.3$ & $5.70 \pm 1.29$ \\
$\mathrm{MRT}, \mathrm{hr}$ & $14.56 \pm 3.9$ & $0.85^{* *} \pm 0.26$ \\
$\mathrm{Cl} / F, \mathrm{~mL} / \mathrm{min}$ & $4.13 \pm 0.57$ & & \\
$V_{\mathrm{ss}} / F, \mathrm{~L} / \mathrm{kg}$ & $0.24 \pm 0.04$ & & \\
\hline
\end{tabular}

${ }^{*} P<.05,{ }^{* *} P<.01$, and ${ }^{* * *} P<.001$

TABLE 3: Compartmental analysis of fluconazole given orally as a single and repeated doses and in combination with fluoxetine (mean \pm $\mathrm{SD})$.

\begin{tabular}{lccr}
\hline Parameters & Single-dose & Multiple-dose & Combination \\
\hline$\alpha$, hr- 1 & $0.427 \pm 0.196$ & $0.276 \pm 0.140$ & $0.390 \pm 0.072$ \\
$\beta$, hr- 1 & $0.039 \pm 0.0189$ & $0.0452 \pm 0.015$ & $0.028 \pm 0.009$ \\
$k_{\mathrm{a}}$ & $1.353 \pm 0.951$ & $1.208 \pm 0.606$ & $0.705 \pm 0.287$ \\
$t_{1 / 2, \alpha}$ & $1.92 \pm 1.049$ & $3.123 \pm 1.360$ & $1.822 \pm 0.302$ \\
$t_{1 / 2, \beta}$ & $21.552 \pm 9.907$ & $16.113 \pm 3.437$ & $27.545 \pm 9.796$ \\
$t_{1 / 2, \mathrm{abs}}$ & $0.686 \pm 0.331$ & $0.729 \pm 0.408$ & $1.138 \pm 0.465$ \\
$C_{\max }$ & $12.05 \pm 4.855$ & $36.882 \pm 3.683$ & $26.68 \pm 6.123$ \\
$T_{\max }$ & $2.762 \pm 1.055$ & $2.233 \pm 0.616$ & $3.152 \pm 1.437$ \\
$r^{2}$ & $0.974 \pm 0.02234$ & $0.996 \pm 0.003$ & $0.988 \pm 0.0113$ \\
\hline
\end{tabular}


not significant $(P>.05)$. Moreover, the time to reach $C_{\max }$ was much longer following the administration of fluoxetine; $3.15 \pm 1.44$ versus $2.23 \pm 0.62$ hours; yet the difference was not significant. On the other hand, a decline in the elimination rate constant $\beta$ was observed following the fluoxetine treatment. One way analysis of variance of the three groups indicated that there is a significant difference among them $(F=5.355 ; P<.05)$. The TukeyKramer multiple comparison showed significant differences in $\beta$ between the multiple fluconazole and the combination groups; $0.045 \pm 0.015$ versus $0.028 \pm 0.01(P<.05)$.

\section{Discussion}

Fluconazole has become the mainstay in the treatment of opportunistic fungal infections in immunocompromized patients [10]. Drug interactions can arise with virtually any antifungal therapy and occur primarily in the gastrointestinal tract, liver and kidneys by several diverse mechanisms. The majority of drug interactions are pharmacokinetic in nature, resulting in changes in the absorption, elimination or metabolism of the interacting drug as well as the antifungal agent [11]. Changes in gastric $\mathrm{pH}$, complexation with ions in the gastrointestinal tract, or interference with transport and enzymatic processes in the intestinal lumen can interfere with drug reaching the systemic circulation. Induction or inhibition of metabolism in the liver can inhibit or accelerate, respectively, drug clearance from the body. The antidepressant fluoxetine is a selective serotonine reuptake inhibitor. Fluoxetine has already been administered to approximately nine million patients worldwide and is therefore a very important drug in antidepressant therapy. Because fluoxetine is a substrate to the cytochrome enzyme CYP2D6 and is an inhibitor of CYP2C19 and thus it has the potential to influence the metabolic elimination of other drugs [12]. SSRIs are also weak inhibitors of CYP3A and the following order is observed: nefazodone $>$ fluvoxamine $>$ norfluoxetine $>$ fluoxetine $>$ sertraline $>$ desmethylsertraline $>$ paroxetine $>$ venlafaxine [13]. Most of the interactions involving fluoxetine have involved mainly the metabolism of the co-administered drug. Several clinically important cardiac events have been reported in patients receiving fluoxetine or fluovoxamine with terfenadine or estemizole [14-16]. A study of the pharmacokinetic effects of fluoxetine on olanzapine was conducted and found to be statistically significant [17]. The mechanism of action of this effect was interpreted as an inhibition of CYP2D6, which is known to control a minor pathway of olanzapine metabolism.

From the above, we can conclude that the interaction with fluoxetine with other concomitantly administered drugs was mainly due to an inhibitory effect on the metabolizing enzymes with an end result of increase in AUC and $C_{\max }$ for most of the cases. In the current study we expected that an effect of fluoxetine would be on either the metabolizing enzyme of fluconazole (although the metabolic clearance of fluconazole is a minor pathway) or on the competitive binding of fluconazole to Cytochrome p450. However, the opposite effect was seen in our study. The results indicated that concurrent administration of fluoxetine significantly reduced both the $\mathrm{AUC}_{0-\infty}$ and $C_{\max }$ of fluconazole by $40.1 \%$ and $35.6 \%$, respectively. In addition a significant reduction in $K_{\mathrm{el}}$ was also observed. Despite the fact that the half-life of fluconazole after multiple-dose was calculated based on 24 hours sampling, however similar half-life was reported for the dog at similar condition [18]. Consequently, an increase in $t_{1 / 2}, \mathrm{MRT}$ and $V_{\mathrm{ss}} / F$ of fluconazole at steady-state was observed after the co-administration of fluoxetine. The increase in $V_{\text {ss }} / F$ value could be due to the reduction in $F$. No significant difference was seen in $\mathrm{Cl} / \mathrm{F}$.

This interaction seems to be due to an inhibitory effect on the absorption of fluconazole and not on the metabolizing enzyme. There is a widespread recognition that the intake of food, beverage or drugs can alter the rate and extent of drug absorption. The alteration might arise from effects on physiological factors including gastric $\mathrm{pH}$, gastric emptying time, intestinal motility, and so forth. The acceleration of transit through the gastrointestinal tract would result in reduced absorption of drugs [19]. Drugs that increase gastric $\mathrm{pH}$ (e.g., $\mathrm{H}_{2}$ antagonists and proton pump inhibitors) could slow the dissolution of the solid dosage forms of other drugs such as ketoconazole and itraconazole $[11,20]$ and decrease drug available for absorption in the intestinal lumen. Other pharmacokinetic studies have documented 30 $60 \%$ reductions in serum itraconazole concentrations $\left(C_{\max }\right.$, $\left.\mathrm{AUC}_{0-24}\right)$ in healthy volunteers administered itraconazole capsules with either famotidine or omeprazole [21-23]. On the contrary; fluconazole seems not to be affected by the change of the gastric $\mathrm{pH}$. In a clinical study conducted by Blum et al. [24], the authors investigated the effects of cimetidine induced increases in gastric $\mathrm{pH}(\mathrm{pH}=6)$ on the relative bioavailability of fluconazole and ketoconazole. There was a dramatic effect on the disposition of ketoconazole with more than $90 \%$ reduction in AUC and $C_{\max }$ values. However, the disposition of fluconazole was not affected by the concomitant administration of cimetidine. The authors explained that since fluconazole has a pka of 1.5 while that of ketoconazole is 6.5 ; this would allow for dissolution at a higher $\mathrm{pH}$ [24]. From the above study, it is clear that gastric $\mathrm{pH}$ has a minor effect on the dissolution and absorption of fluconazole. The compartmental analysis of the plasma concentration-time data of both steady-state fluconazole alone and in combination of fluoxetine indicated that there is a reduction in the absorption rate constant of fluconazole. Different mechanisms could be involved in the decrease in the rate and extent of absorption of fluconazole. It is appreciated that drug efflux by P-glycoprotein (P-gp) and organic anion transport polypeptide (OATP) play an important role in the disposition of many drugs. Fexofenadine oral bioavailability was significantly decreased by fruit juices and the authors suggested an inhibition of OATPmediated drug uptake as the responsible mechanism for this reduction [25]. Xenobiotics that act as substrates for OATP can also serve as substrates for P-gp; consequently they may represent an important factor in drug interaction $[25,26]$. Azoles such as fluconazole and others can be both substrate and inhibitor of the P-gp; making the effects of P-gp efflux on azole absorption difficult to predict in individual patients $[27,28]$. 
In an attempt to explain the results observed in this study, we suggest several alternative mechanisms. The first mechanism could have been that fluoxetine increased the P-gp mediated efflux transport of fluconazole, leading to decreased absorption; however, in vitro data suggests that fluoxetine inhibits P-gp function [29]. Second, fluoxetine may have reduced fluconazole AUC by inhibiting uptake transporters of the intestine such as OATP and thus reducing the oral availability of fluconazole. Nevertheless it is still not well known whether fluconazole is a substrate for OATP. Alternatively, fluoxetine could compete with fluconazole for another transporter-mediated uptake process during absorption. Repeating the current experiment using intravenous route of administration could shed a light on the exact mechanism involved in this interaction.

To conclude, fluoxetine reduced plasma concentration of fluconazole. The mechanism of the interaction is probably inhibition of OATP or other transporters in the intestinal wall. This interaction may have significant clinical importance because reduction in fluconazole may lead to treatment failure of fungal infection and possible serious consequences especially in immunocompramised patients who depend on such drugs for prevention and prophylaxis of serious opportunistic infections.

\section{References}

[1] T. Shimada, H. Yamazaki, M. Mimura, Y. Inui, and F. P. Guengerich, "Interindividual variations in human liver cytochrome P-450 enzymes involved in the oxidation of drugs, carcinogens and toxic chemicals: studies with liver microsomes of 30 Japanese and 30 Caucasians," Journal of Pharmacology and Experimental Therapeutics, vol. 270, no. 1, pp. 414-423, 1994.

[2] M. T. Pasko, S. C. Piscitelli, and A. D. Van Slooten, "Fluconazole: a new triazole antifungal agent," DICP, vol. 24, no. 9, pp. 860-867, 1990.

[3] R. L. Slaughter and D. J. Edwards, "Recent advances: the Cytochrome P450 enzymes," Annals of Pharmacotherapy, vol. 29, no. 6, pp. 619-624, 1995.

[4] K. Richardson, "The discovery and profile of fluconazole," Journal of Chemotherapy, vol. 2, no. 1, pp. 51-54, 1990.

[5] P. Benfield, R. C. Heel, and S. P. Lewis, "Fluoxetine. A review of its pharmacodynamic and pharmacokinetic properties, and therapeutic efficacy in depressive illness," Drugs, vol. 32, no. 6, pp. 481-508, 1986.

[6] S. H. Preskorn, R. Shah, M. Neff, A. L. Golbeck, and J. Choi, "The potential for clinically significant drug-drug interactions involving the CYP 2D6 system: effects with fluoxetine and paroxetine versus sertraline," Journal of Psychiatric Practice, vol. 13, no. 1, pp. 5-12, 2007.

[7] R. M. Lane, "Pharmacokinetic drug interaction potential of selective serotonin reuptake inhibitors," International Clinical Psychopharmacology, vol. 12, no. 2, p. 126, 1997.

[8] J. F. Wernicke, "Safety and side effect profile of fluoxetine," Expert Opinion on Drug Safety, vol. 3, no. 5, pp. 495-504, 2004.

[9] J. Amchin, L. Ereshefsky, W. Zarycranski, K. Taylor, D. Albano, and P. M. Klockowski, "Effect of venlafaxine versus fluoxetine on metabolism of dextromethorphan, a CYP2D6 probe," Journal of Clinical Pharmacology, vol. 41, no. 4, pp. 443-451, 2001.
[10] S. M. Grant and S. P. Clissold, "Fluconazole: a review of its pharmacodynamic and pharmacokinetic properties, and therapeutic potential in superficial and systemic mycoses," Drugs, vol. 39, no. 6, pp. 877-916, 1990.

[11] P. O. Gubbins, S. A. McConnell, and S. R. Penzak, "Antifungal Agents," in Drug Interactions in Infectious Diseases, S. C. Piscitelli and K. A. Rodvold, Eds., Humana Press, Totowa, NJ, USA, 2001.

[12] L. L. Von Moltke, D. J. Greenblatt, J. Schmider, et al., "Midazolam hydroxylation by human liver microsomes in vitro: inhibition by fluoxetine, norfluoxetine, and by azole antifungal agents," Journal of Clinical Pharmacology, vol. 36, no. 9, pp. 783-791, 1996.

[13] T. A. Ketter, D. A. Flockhart, R. M. Post, et al., "The emerging role of cytochrome P450 3A in psychopharmacology," Journal of Clinical Psychopharmacology, vol. 15, no. 6, pp. 387-398, 1995.

[14] Solvay's Luvox, "Contraindication against co-administration with J\&J's Hismanal, MMD's Seldane prompts FDA review of other SSRI labelling," FDC Reports, The Pink Sheet, 1995.

[15] R. J. Marchiando, M. D. Cook, and S. G. Jue, "Probable terfenadine-fluoxetine-associated cardiac toxicity," Annals of Pharmacotherapy, vol. 29, no. 9, pp. 937-938, 1995.

[16] M. J. Cupp and T. S. Tract, "Cytochrome P450: new nomenclature and clinical implications," American Family Physician, vol. 57, no. 1, pp. 107-116, 1998.

[17] D. Gossen, J. M. de Suray, F. Vandenhende, C. Onkelinx, and D. Gangji, "Influence of fluoxetine on olanzapine pharmacokinetics," AAPS PharmSci, vol. 4, no. 2, p. E11, 2002.

[18] M. J. Humphrey, S. Jevons, and M. H. Tarbit, "Pharmacokinetic evaluation of UK-49,858, a metabolically stable triazole antifungal drug, in animals and humans," Antimicrobial Agents and Chemotherapy, vol. 28, no. 5, pp. 648-653, 1985.

[19] N. K. Wadhwa, T. J. Schroeder, E. O'Flaherty, A. J. Pesce, S. A. Myre, and M. R. First, "The effect of oral metoclopramide on the absorption of cyclosporine," Transplantation, vol. 43, no. 2, pp. 211-213, 1987.

[20] D. Lange, J. H. Pavao, J. Wu, and M. Klausner, "Effect of a cola beverage on the bioavailability of itraconazole in the presence of H2 blockers," Journal of Clinical Pharmacology, vol. 37, no. 6, pp. 535-540, 1997.

[21] S. Jaruratanasirikul and S. Sriwiriyajan, "Effect of omeprazole on the pharmacokinetics of itraconazole," European Journal of Clinical Pharmacology, vol. 54, no. 2, pp. 159-161, 1998.

[22] Y. Kanda, M. Kami, T. Matsuyama, et al., "Plasma concentration of itraconazole in patients receiving chemotherapy for hematological malignancies: the effect of famotidine on the absorption of itraconazole," Hematological Oncology, vol. 16, no. 1, pp. 33-37, 1998.

[23] A. Johnston, "The pharmacokinetics of voriconazole," British Journal of Clinical Pharmacology, vol. 56, supplement 1, p. 1, 2003.

[24] R. A. Blum, D. T. D’Andrea, B. M. Florentino, et al., "Increased gastric $\mathrm{pH}$ and the bioavailability of fluconazole and ketoconazole," Annals of Internal Medicine, vol. 114, no. 9, pp. 755-757, 1991.

[25] G. K. Dresser, D. G. Bailey, B. F. Leake, et al., "Fruit juices inhibit organic anion transporting polypeptide-mediated drug uptake to decrease the oral availability of fexofenadine," Clinical Pharmacology and Therapeutics, vol. 71, no. 1, pp. 1120, 2002.

[26] A. V. Kamath, M. Yao, Y. Zhang, and S. Chong, "Effect of fruit juices on the oral bioavailability of fexofenadine in rats," 
Journal of Pharmaceutical Sciences, vol. 94, no. 2, pp. 233-239, 2005.

[27] S. D. Hall, K. E. Thummel, P. B. Watkins, et al., "Molecular and physical mechanisms of first-pass extraction," Drug Metabolism and Disposition, vol. 27, no. 2, pp. 161-166, 1999.

[28] E.-J. Wang, K. Lew, C. N. Casciano, R. P. Clement, and W. W. Johnson, "Interaction of common azole antifungals with P glycoprotein," Antimicrobial Agents and Chemotherapy, vol. 46, no. 1, pp. 160-165, 2002.

[29] C. M. Pariante, R. B. Kim, A. Makoff, and R. W. Kerwin, "Antidepressant fluoxetine enhances glucocorticoid receptor function in vitro by modulating membrane steroid transporters," British Journal of Pharmacology, vol. 139, no. 6, pp. 1111-1118, 2003. 